\title{
Technical transformation researches and practices of papermaking wastewater treatment project
}

\author{
PENG Mingjiang \\ Chengdu technological university, Sichuan Chengdu 610031, China
}

\begin{abstract}
KEYWORD: papermaking wastewater; Technical transformation; Project practice
ABSTRACT: papermaking midcourse water is the most important papermaking wastewater, whose concentration of pollutants is relatively high with large amount of water and produces big hazards to the environment. The article introduces the general situations of technical transformations, and compares the removal effects and treatment compliance situations of the major pollutants in the papermaking midcourse water by the wastewater treatment project before and after the technical transformations, and on this basis, it analyzes the process and technology features of the technical transformation project. The project practices show that the operations of the papermaking wastewater treatment project system after the technical transformations are reliable and able to tolerate the impact loads, and the treatment effects are significantly improved. The technical transformation method has reference values to the treatment of the papermaking midcourse water.
\end{abstract}

\section{INTRODUCTION}

Since July 1, 2011 the wastewater discharged by the pulp and paper enterprises should reach the water pollutant limited standard in Table2 of Discharge Standard of Water Pollutants for Pulp and Paper Industry, the new and stricter discharge standard requires that the pulp and paper enterprises must adopt more effective and reliable waste water treatment technology to manage the waste water (mainly the midcourse water) [1].

A papermaking enterprise in Sichuan adopted the "hydrolytic acidification + traditional activated sludge method" to manage the papermaking midcourse water, while the treatment results always fails to stably reach the standard. in order to guarantee that the wastewater treatment reaches the new and strict industry standard, after analyzing the problems existing in the previous wastewater treatment technology, it decides to perform the technical transformations, and cancels the anaerobic biological treatment step, and changes the hydrolytic acidification tank into the accident pool; adopts the "improved oxidation ditch + air flotation group technology" to manage the papermaking midcourse water. The planning and practice conditions of the technical transformation project of this papermaking waste water treatment will be analyzed and discussed as follows.

\section{General situations of the technical transformation project}

\section{The previous waste water treatment process}

Before the technical transformations, the designed treatment capability of the waste water treatment project is $600 \mathrm{~m}^{3} / \mathrm{h}$, and the waste water treatment project system is seen in Figure 1 .

The papermaking midcourse water is collected through the drain-pipes, and it will be sent to the sewage treatment station by the sewage lift pumps. In the sewage treatment station, firstly it will pass the slope screen to recover the coarse fibers, and then enter into the buffer tank to perform the homogeneous and average adjustment, later enter into the primary sedimentation tank, where the sewages will be subsided to perform the mud-water separation to remove the most suspended matters, and then enter into the hydrolytic acidification tank to transfer the insoluble organic matters into the soluble organic matters, and meanwhile transfer the organic matters which are difficult to be biodegraded into the organic matters which are easy to be biodegraded, and improve the biodegradability of the waste water for the successive aerobic treatment, and then the waste water enters into the traditional activated sludge aeration tank to perform the aerobic biodegradation to remove the most organic matters, and the aeration tank mixed liquor performs solid-liquid separation in the secondary sedimentation tank, and the supernatant of the the secondary sedimentation tank, that is to say the treatment effluent, will be directly discharged. 


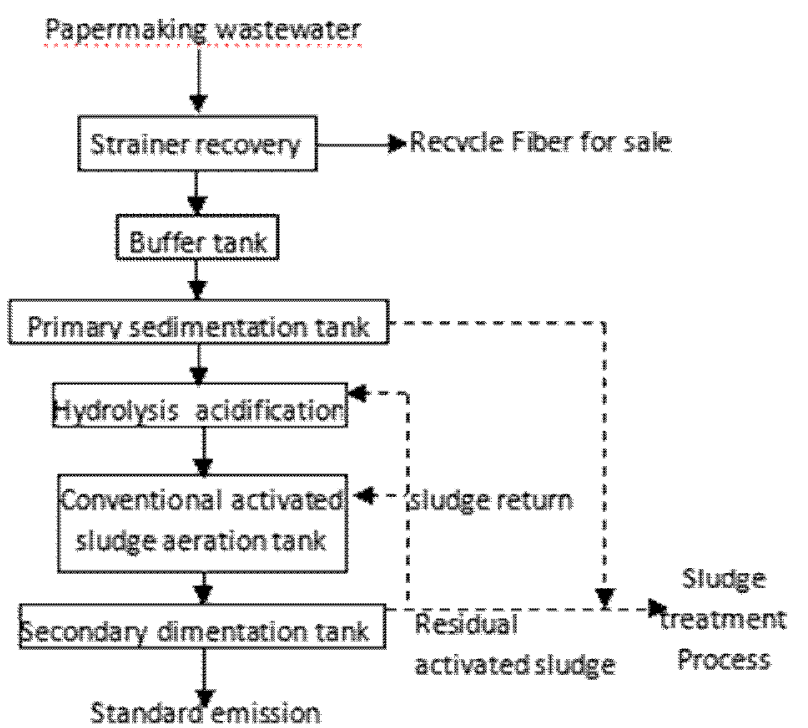

Figure 1. The waste water treatment project system before the technical transformations.

\section{The waste water treatment process after the technical transformations}

The designed treatment capability of the waste water treatment project after the technical transformations is $750 \mathrm{~m}^{3} / \mathrm{h}$, and the waste water treatment project system is seen in Figure 2 .

The papermaking midcourse water enters into the Carrousel oxidation ditch after passing the strainer, buffer tank and primary sedimentation tank. The oxidation ditch adopts the vertical surface aerator and added with packing, resolve and absorbs most organic pollutants by using the suspending growth aerobic microorganisms and the packing-attached growth aerobic microorganisms, the oxidation ditch effluent enters into the secondary sedimentation tank for solidliquor separation, and the secondary sedimentation tank effluent enters into the air flotation tank further to remove the residual suspended solids by the super-efficient micro air flotation.

Deliver the activated sludge pump subsided in the secondary sedimentation tank to the Carrousel oxidation ditch, and the residual activated sludge (whose moisture content is about $98.5 \%$ ) and the sludge in the primary sedimentation tank are discharged into the sludge concentration tank for concentration(till the moisture content of 97.5\%), and then enter into the dewatering room to be dewatered into mud cakes(whose moisture content is about $70 \%$ ), and finally transported outside for sanitary landfill.

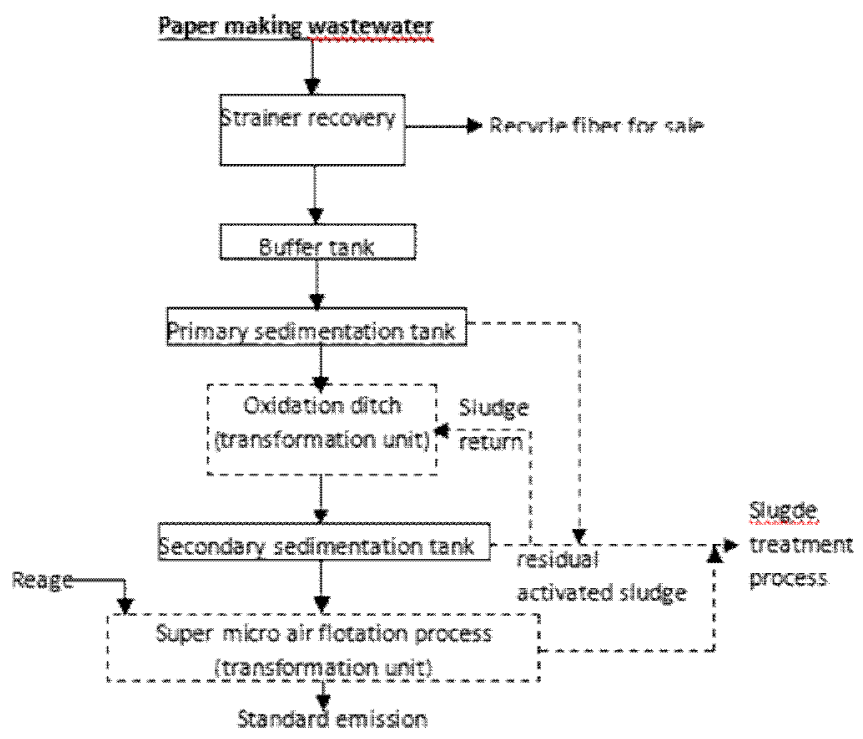

Figure 2. The waste water treatment project system after the technical transformations.

The technical transformations removes the anaerobic biochemical treatments for the consideration of the worse hydrolytic acidification treatment effects and low removal rate to 
$\operatorname{COD}$ (the removal rate only 5\% 10\%) and un-conspicuous improvements to the biodegradability, it is believed in the analysis that this might be concerned with the bleaching chlorine products influencing the anaerobic bacteria activities, and resulting to the low anaerobic treatment efficiency. Adopting the improved oxidation ditch technology (adding packing to the Carrousel oxidation ditch) to replace the traditional activated sludge method is for the consideration that the oxidation ditch has the advantages of strong ability against the impact loads, good adaptability, thorough pollutant treatment. While adding the packing, the activities and concentrations of the microorganisms are improved, thus it helps to improve the aerobic biological treatment efficiency in the aerobic bioreactor. The technical transformations of this project post the air flotation at the end of the process is mainly to remove the chromatic organic matters and suspended solids which are difficult to be degraded, the adopted super-efficient micro air flotation technology is fused with the "Zero-velocity Principle", "Shallow -tank Principle" as well as the new air dissolution mechanism, and it have very high air dissolution and air flotation efficiencies, and have high removal rate to suspended solids and chromaticity, Thus it can better guarantee the standard emission of the effluent.

\section{Comparative analysis of the waste water treatment operation efficiency before and after the technical transformations}

\section{The operation situations of the previous waste water treatment system before the technical} transformations

According to the on-line monitoring data half a year before the technical transformations, the effluent indexes of the previous waste water treatment system (including COD, SS and chromaticity) are as follows:

The average concentration of $\mathrm{COD}_{\mathrm{Cr}}$ in each month is all about $86 \mathrm{mg} / \mathrm{L}$, and the month average maximum value is $101.8 \mathrm{mg} / \mathrm{L}$, and the minimum value is $66 \mathrm{mg} / \mathrm{L}$; the average concentration of SS in each month is all about $52 \mathrm{mg} / \mathrm{L}$, and the month average maximum is $79 \mathrm{mg} / \mathrm{L}$, the minimum value is $38 \mathrm{mg} / \mathrm{L}$; the chromaticity average value in each month is all about 62 times, and the month average maximum value is 78 times, and the minimum value is 45 times, each item can't stably reach the standard.

\section{The operation effects of the new waste water treatment system after the technical transformations}

After the technical transformation project system is put into operation, with the continuous operations in 9 months, it monitors the effluent indexes (including COD, SS and chromaticity) in real time through the on-line monitoring system are seen in Figure 3.

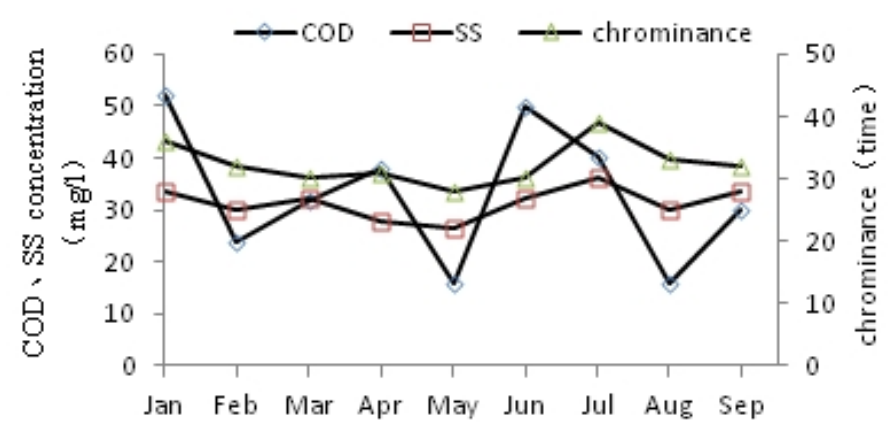

Figure 3. The effluent effect of the new waste water treatment system after the technical transformations.

From Figure 3 it can be seen that, the average concentration of $\mathrm{COD}_{\mathrm{Cr}}$ in each month is all about $30 \mathrm{mg} / \mathrm{L}$, and the month average maximum value is $51.8 \mathrm{mg} / \mathrm{L}$, the minimum value is $15 \mathrm{mg} / \mathrm{L}$, which are all far lower than $90 \mathrm{mg} / \mathrm{L}$, regulated by the industry water pollutant emission standard; the average concentration of SS in each month is all about $26 \mathrm{mg} / \mathrm{L}$, and the month average 
maximum value is $28.2 \mathrm{mg} / \mathrm{L}$, and the minimum average value in each month is $22.6 \mathrm{mg} / \mathrm{L}$, which are all lower than $30 \mathrm{mg} / \mathrm{L}$, regulated by the industry water pollutant emission standard; the average value of the chromaticity in each month is all about 33 times, and the month average maximum value is 39 times, and minimum value is 29times, which are all lower than 50 times, regulated by the industry water pollutant emission standard.

Before and after the technical transformations, the water quantity and quality of the papermaking waste water entering into the sludge treatment system basically remains the same, and the effluent effect comparison of the waste water treatment system is seen in Table 1.

Table 1. The effluent effect comparisons of the wastewater treatment before and after the technical transformations.

\begin{tabular}{lllc}
\hline \multirow{2}{*}{ indexes } & $\mathrm{COD}_{\mathrm{Cr}}$ & $\mathrm{SS}$ & chrominance \\
\cline { 2 - 4 } & $\mathrm{mg} / \mathrm{L}$ & $\mathrm{mg} / \mathrm{L}$ & time \\
\hline $\begin{array}{l}\text { Before the } \\
\text { technical } \\
\text { transformations }\end{array}$ & 86 & 52 & 62 \\
$\begin{array}{l}\text { After the } \\
\text { technical } \\
\text { transformations }\end{array}$ & 30 & 26 & 33 \\
$\begin{array}{l}\text { Pollutant } \\
\text { emission }\end{array}$ & $65 \%$ & $50 \%$ & $47 \%$ \\
$\begin{array}{l}\text { reduction } \\
\text { Emission }\end{array}$ & 90 & 30 & 50 \\
standard & & & \\
\hline
\end{tabular}

* Water quality indexes are average values of each month.

From Table 1 it can be seen that, the technical transformations have significantly improved the waste water treatment efficiency, and each item in the treatment effluent all has been significantly improved, COD reduces emission of $65 \%$, SS reduces emission of $50 \%$, and the chromaticity reduces emission of $47 \%$, the improved oxidation ditch (added with packing) after the technical transformations and the super-efficient micro air flotation system have good effects on the papermaking midcourse water treatment, the emission concentration of the main pollutants $\left(\mathrm{COD}_{\mathrm{Cr}} 、 \mathrm{SS}\right.$ and chromaticity) is low, and the long-term standard emission has been realized, the system operation is stable and reliable with good adaptability to the water quality and water quantity load impact.

During the operation of the technical transformation project, two relatively comprehensive water quality monitorings have been performed on the waste water discharged by the sewage treatment devices in this paper mill in the first and third quarters, whose treatment situations are seen in Table 2. From Table 2 it can be seen that, each index of the treatment effluent all reaches the limit value requirements in limited standard in Table 2 of Discharge Standard of Water Pollutants for Pulp and Paper Industry (GB3544-2008), that is to say, $\mathrm{COD}_{\mathrm{Cr}} \leq 90 \mathrm{mg} / 1$ 、 $\mathrm{BOD}_{5} \leq 20 \mathrm{mg} / \mathrm{l}$ 、 $\mathrm{SS} \leq 30 \mathrm{mg} / 1 、 \mathrm{NH}_{3}-\mathrm{N} \leq 8 \mathrm{mg} / \mathrm{l}$ 、 chromaticity $\leq 50$, reaches the standard emission. 
Table 2. The effluent quality of the new waste water treatment system by comprehensive

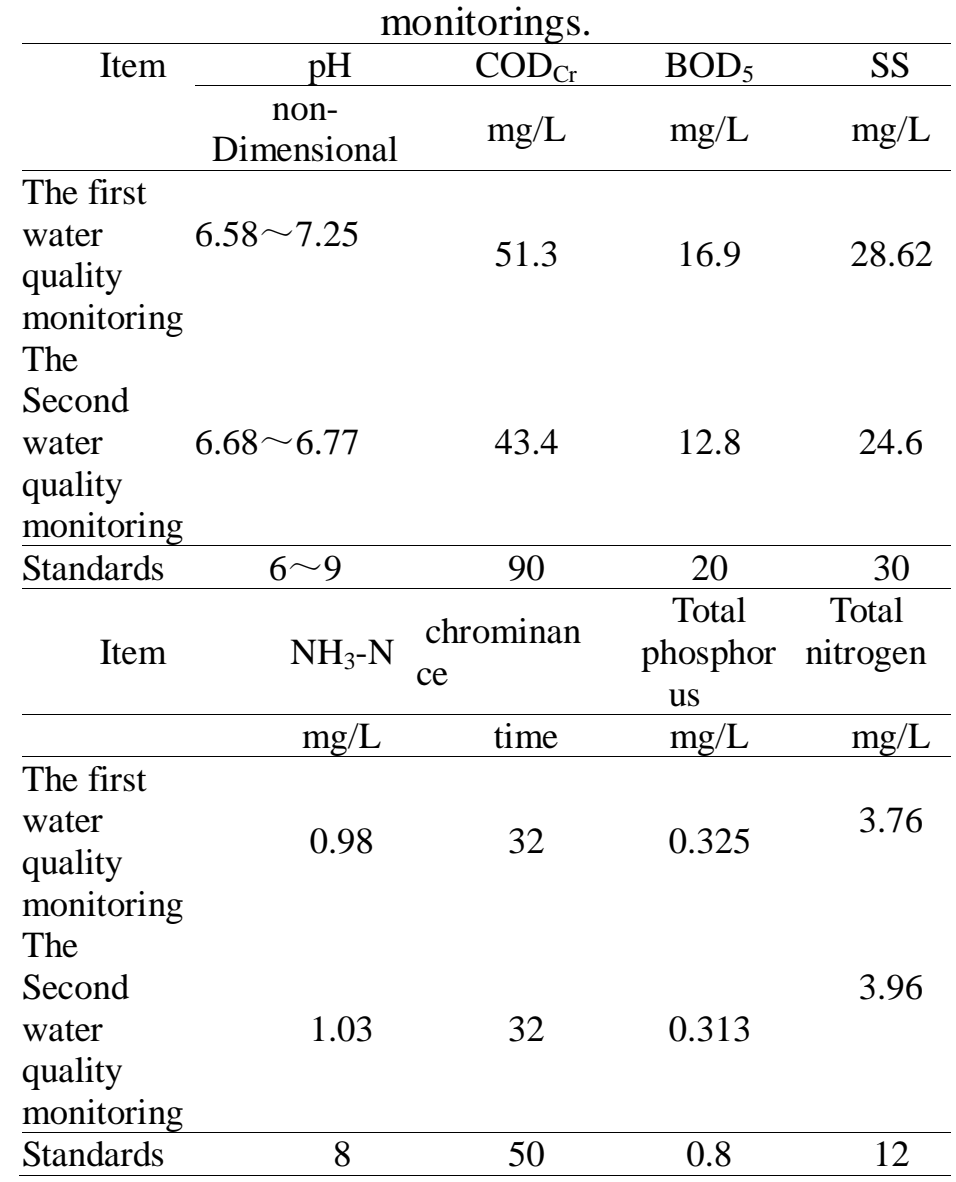

\section{Analysis of the technical transformation process features}

\section{Technical features of the improved oxidation ditch}

The oxidation ditch is actually a modification of the activated sludge method; it is also called "continuous aeration tank", "non-terminal aerating system" because the mixed liquor of the waste water and activated sludge is continuously flowing inside the ring-like aeration corridor. It is believed by the analysis that the treatment midcourse water of the improved oxidation ditch process has the following advantages:

1)The flow mixed features of the oxidation ditch are between the plug-flow type and completely mixed type, that is to see with a view to the whole oxidation ditch and see from the relatively time, it can be believed that the oxidation ditch is a completely mixed tank, whose mixed liquor quality basically remains basically the same, and the raw water is diluted by the circulation flow of dozens times even hundreds times, once it enters into the oxidation ditch, hence the oxidation ditch is capable of managing the organic waste water of high and medium concentrations, and standing the impact of the water quantity and water quality changes. The flow mixed features of the oxidation ditch make it have obvious advantages in the industrial waste water treatment, and it has been gradually noticed and applied in the papermaking industry.

2)The oxidation ditch process usually adopts the low-load operation, and the hydraulic retention time is longer than the traditional activated sludge method with long system sludge age, hence the water pollutant treatment is relatively complete with stable treatment results, and the effluent quality is generally good.

3)After the oxidation ditch is added with packing, it makes the growth of the microorganisms have both the features of the activated sludge process and the biofilm process, the microbial morphologies are richer and the micro ecological food-chain is longer, so the activities and concentrations of the microorganisms are significantly improved, thus the treatment efficiency and effluent quality have been further improved. 


\section{Technical features of the super-efficient micro air flotation technology}

The micro air flotation method has been widely applied in the papermaking waste water treatment field [2][3]. This project adopts the super-efficient micro air flotation, and after the longterm operation, it has obtained good treatment effects, the effluent quality has reached the industry standard for a long time. The super-efficient micro air flotation has creativities in the air flotation theory, and it adopts the zero-velocity principle, that is to say, besides the fixed parts of the tank, all of the other parts rotate at the same velocity with the same velocity of the inlet flow velocity, in order to form the static inlet and static outlet to make the air flotation completed under the relatively static conditions, which has greatly improved the air flotation efficiency; this process also has the features of shallow air flotation tank, and its shallow tank structures have saved the investments, reduced the device spaces, shortened the floc ascent time, and reduced the hydraulic retention time; the new dissolved air pipe has improved the dissolved efficiency, and the formed micro bubbles have very small particle sizes and large quantity, the hybrid dynamical features of the air, water and flocculant are good and in favor of forming the floc.

The papermaking midcourse water, after the biological treatment and secondary sedimentation, still contains certain amounts of organic colloids which are difficult to be degraded, and has certain chromaticity, which makes it difficult to reach the standard emission. By adopting the highefficiency air flotation process of super-efficient flotation, the kinetic energies of micro bubbles quick expansion will be delivered to colloids to make their thermal velocity increased, and the colloids impact with each other to make it destabilized and Formation of floc, and the short chain organic molecules and nonferrous groups in the waste water be attached in great amount, in order to reach the purpose of greatly improving the removals of the organic matters which are difficult to be degraded even by the biochemistry and physic-chemistry treatment, and have important roles in reaching the standard emission. It can be seen from the above analysis that, the super-efficient micro air flotation has the features of less land occupation, saving investment and high air flotation efficiency, which is very suitable to the deep treatment of papermaking waste water, and it is a very important technical method to guarantee the standard emission.

\section{Conclusions:}

Through the technical transformation researches and practices of the papermaking waste water treatment project, the following conclusions can be obtained:

1)The oxidation ditch has the water flow mixed features between the plug-flow type and completely mixed type; it could bear the impact loads and manage the organic matters of relatively high concentrations, after being added with the packing, the treatment efficiency is high, and water pollutant treatment is thorough,and it is suitable to the biological treatment of the papermaking midcourse water; the super-efficient micro air flotation method applies the new air flotation principle, and the air flotation efficiency of dissolved air is high, and it is suitable to the deep treatment of the papermaking waste water treatment;

2)Combing the oxidation ditch( the improved activated sludge method) with the air flotation method, the comprehensive treatments of the papermaking waste water have the advantages of good treatment effects, stable operation and bearing the impact loads;

3) The project practices show that, under the current situations of taking the midcourse water as the main treatment object for the papermaking industries, the aerobic biologic treatment adopts the oxidation ditch process, and the deep treatment adopts the micro air flotation process, each index of the treatment effluent of this combined treatment process all could reach the stricter concentration limited requirements of "Pulp and Paper Combined Enterprises" in Table 2 of Discharge Standard of Water Pollutants for Pulp and Paper Industry. The technical transformation method has reference values to the treatment of the papermaking midcourse water.

\section{References:}

[1]Zhang Ruixia, Chen Fushan, Liu Tingzhi, Treatment of Pulp and Paper Mill Wastewater-A Review[J], Internal Paper, 2005,24 (6):48-54.

[2]Shi Penghui, Wu Junfeng, Papermaking Wastewater Treatment by Shallow Air Flotation and 
Modified Biolak Process[J], China Pulp \& Paper 2011 Wastewater Treatment Album:243-245. [3]Wu Zhimin, Zhangli, Treatment of Regenerated Papermaking Wastewater By High-efficiency Air Floating-Hydrolysis-Aerobic Process [J] Technology of Water Treatment, 2009,7:104-106. 